\title{
The Impact of Use of Manipulatives on the Math Scores of Grade 2 Students
}

\author{
Robert Scott Liggett \\ University of Saskatchewan
}

\begin{abstract}
Today's society places a lot of pressure on schools, teachers, and students to improve test scores. This paper discusses the possibility of using mathematical manipulatives to improve student test scores and students' attitudes towards mathematics. Forty-three Grade 2 students with age ranges between six and eight from a rural town in Saskatchewan were selected. They were divided randomly into two groups: the treatment group $(n=22)$ and the control group $(n=21)$ and their pre-and post-test scores compared. Findings supported the hypothesis that students in the treatment group who received the math intervention obtained higher post-test scores in comparison to their classmates in the control group.
\end{abstract}

Keywords: Mathematic pedagogy, manipulatives, elementary, mathematic skills, assessment

Robert Liggett, Ph.D., is a Sessional Lecturer and a Research Associate in the Department of Education Administration at the University of Saskatchewan. He has worked in rural and urban school systems and is a regular presenter at scholarly conferences in educational leadership. Robert is a bilingual educator with over 20 years of relevant experience who continues to consult and contribute to improving achievement in organization's goals and objectives. His research interests are in the areas of organizational theory, educational leadership, and instructional improvement.

Email: robert.liggett@usask.ca

Brock Education Journal, 26(2), 2017 
The purpose of this study was to determine the effect of manipulatives on improving student performance in mathematics. Education is constantly under the microscope. Within education, we are constantly trying to create the ideal school: one that is driven by a vision that involves an element of dreaming about the very best that can happen. Unfortunately, vision without action is merely a dream. Bringing the vision to reality requires the concerted effort of all education stakeholders, and this belief is certainly relevant as we consider mathematics pedagogy. Understandably, math skills are crucial to functioning in today's world (Burns \& Hamm, 2011; Carbonneau, Marley, \& Selig, 2013). These skills are not just important in school mathematical classes; they are important in our daily lives. Golafshani (2013) stated, "There is no doubt that everyone believes that mathematics is important, however, many students have poor math skills, which indicates that changes are needed in the methodology of teaching mathematics" (p. 140). Golafshani (2013) found that there is a growing consensus around the use of manipulatives in instructional practices.

The ancient Chinese proverb, I hear and I forget, I see and I remember, I do and I understand, suggests important aspects of learning in this area. What is the best method that an educator can use in teaching mathematics? By assumption, the best method is one in which the results will increase not only the achievement of students but also their attitude towards mathematics. How often do we hear a group of 5th Grade students say they like doing math? The chances of this happening may improve with the use of mathematical manipulatives (Burns \& Hamm, 2011; Bjorklund, 2014; Carbonneau et al.; Gauthier et al., 2004).

One may inquire as to just what constitutes a manipulative. Johnson (1993) noted, "Manipulatives are objects used for instruction that vary in shape, size, and color" (p. 10). Ultimately, manipulatives can be any objects that an innovative teacher wishes to use to improve a student's mathematical skills. Gauthier (2004) noted that manipulatives have a place not only at the elementary level but also in the higher grades. From starting with simple beans or buttons to using graphing calculators or computer software, students can explore a vast amount of mathematics that often was incomprehensible in the past. The goals of any math instruction should be to focus on helping students understand concepts. The use of manipulatives allows students to see mathematics as integration by relating procedures used in one question to procedures used in an equivalent question.

Mathematical skills are critical to functioning in today's fast moving and changing world. They are skills that students will use in their daily lives, and thus we should be aware of the importance of keeping an open mind about the use of manipulatives. Education professionals are still learning about the effective use of manipulatives. They would do well to embrace the position that math instruction should focus on helping students understand math concepts. Manipulatives used by teachers have potential when used in such a way that they promote reflection on the part of students. Golafshani (2013) found that mathematical instruction should begin with experiences that are real to students and function as symbols throughout their learning, and, clearly, manipulatives represent important tools in efforts to make mathematics more real. However, as with any tool they should be used with caution and care to optimize results. If used inappropriately, they may result in frustration or confusion, and ultimately disrupt student motivation and overall learning opportunities.

School professionals are constantly looking for methods to improve student learning. Achieving this will require effort and the use of multiple strategies or methods. The goal of this quasi- 
experimental study was to provide information about the value of manipulatives as another tool that is available to assist educators in the endeavor of improving student learning.

\section{Statement of Problem}

A report from the Canadian Broadcast Corporation (2016) noted that Saskatchewan students lag behind all provinces in reading, science and math based on a test from the Organization for Economic Co-operation and Development. Arguably, the general need for Saskatchewan students to perform well on school system and provincial assessment exams becomes increasingly pronounced year after year. This has escalated the levels of pressure on teachers and administrators. Teachers struggle to find adequate time to cover all the material demanded by the curriculum and government; they may not be convinced of the benefits of using manipulatives to aid students with different learning styles and they may believe that manipulatives are merely an additional item increasing their workload with limited promise of success (Golafshani, 2013). Many teachers continue to rely on traditional teaching methods (Mura, 1995). Golfashani (2013) found that the utilization of only one instructional approach results in meeting the learning styles of a few students while those of many other students are ignored. This in turn results in students developing negative self-concept regarding their mathematical abilities, accompanied by a consequent lack of enthusiasm for learning mathematics, which in turn would likely hinder levels of improvement in mathematical skills.

In light of the argument from Golfashani (2013) that traditional approaches are insufficient, the problem requiring investigation is: Does incorporating the use of manipulatives as a teaching method improve student learning of mathematics? Specifically: Are there group differences in the post measure test scores between students who use manipulatives and those who do not, when we control for their pre-test scores, gender and ethnicity? The one-tailed hypothesis $(\alpha=0.05)$ was that Grade 2 students who use manipulatives will perform higher in their post-test scores.

\section{Research Question}

The question becomes, to what extent does the use of mathematical manipulatives improve test scores for Grade 2 students at a school in Saskatchewan? The null hypothesis was that there is no significant difference in test scores between the two groups. This researcher hypothesized that when manipulatives are used with a group of Grade 2 students in one Saskatchewan school, the higher the post-test scores will be.

\section{Related Studies}

Teaching mathematics by using manipulatives has a long history. There has been considerable research completed on the use of manipulatives towards the goal of aiding students to better understand math concepts (Bjorklund, 2014; Burns \& Hamm, 2011; DeLoache, Scudder \& Uttal, 1997; Driscoll, 1983; Freer, 2006; Moyer \& Jones, 2006; Raphael \& Wahlstrom, 1989; Sowell, 1989; Suydam \& Higgins, 1977; Swan \& Marshall, 2010).

Some contradictory research indicated that the use of manipulatives is no more effective than other traditional methods of teaching (Eastman \& Barnett, 1979; Fennema, 1972). One such study completed by Fennema (1972) involved 95 subjects from the age ranges of 7 to 8 years old. They 
were divided into two groups: symbolic and concrete. The concrete group used Cuisenaire rods to answer some math questions and the symbolic group did not. The result was that the children learned better without the manipulative. Fennema (1972) stated, "It does not indicate that the concrete models are not always more effective than symbolic models" (p. 238). Thus, this early study demonstrated that the evidence of the benefits of using manipulatives was far from conclusive.

A study conducted by Eastman and Barnet (1979) resulted in the same conclusion. The study involved 78 university elementary majors. From this educational group, 39 students were placed in an experimental group who could use manipulatives and 39 were placed in a control group without the use of materials. Eastman and Barnett concluded, "In no instance did the experimental (hands on) group perform better than the control group, either on the paper-scored tests or on the tasks where both groups were asked to demonstrate the ability to manipulate the materials" ( $p$. 212). This research seemed to indicate that manipulatives do not aid in improving student learning of mathematics.

However, most of the research points towards the use of manipulatives as a positive tool to improve student learning within mathematics (Parham, 1983; Raphael \& Wahlstrom, 1989; Sowell, 1989; Suydam \& Higgins, 1979). Suydam and Higgins (1977) observed, "the overall point remains, however; far more of the studies favor the use of materials than favor non-use of materials" (p. 18). Much of the literature impacts this current study. This review will provide a chronological perspective regarding the importance of using manipulatives in mathematics.

Some of the earliest research completed in the 1960s and 1970s found mixed results of manipulatives such as concrete or pictorial materials in instruction. The problem with this early research (Kieren, 1971) was that it simply summarized the findings. There was no experimental process utilized as part of this research as there were no classroom observations conducted. As a result, there were no declarations on the belief that manipulatives were beneficial to students. This in turn left the readers to formulate their own conclusions about the effectiveness of manipulatives.

Friedman (1978) conducted an investigative review of 15 studies conducted prior to 1970 that were concerned with elementary school instruction. Friedman's research, dated but still relevant, showed that manipulatives were beneficial for young children but not for older children regarding their learning. In 1977 Suydam and Higgins released the first comprehensive review of over 20 studies involving activity-based learning in mathematical instruction from kindergarten to Grade 8. While this review is notably dated, their review found that using manipulative materials produced greater achievement than not using them at all the levels of elementary school.

Additional research in the 1980s (Parham, 1983) supported the research of Suydam and Higgins regarding the benefits of using manipulatives in mathematics. Further research (Driscoll, 1983; Raphael \& Wahlstrom, 1989; Sowell, 1989) found that students from kindergarten to college age, who use manipulatives in their mathematics class usually outperform those who do not. Furthermore, Sowell (1989) found that attitudes towards mathematics are improved when students have instruction with concrete materials provided by the teachers who are knowledgeable about their use. Further, a study by DeLoache, Scudder and Uttal in 1997 involving young children supported the practice of using manipulatives in mathematics by revealing that concrete objects can help children gain access to concepts and mathematical processes that might otherwise remain a mystery.

Increasingly, educators are coming to understand that manipulative materials are designed to help students at all ages and learning levels. Suydham and Higgins' (1977) investigative review of 
the literature found that the studies support the idea that activity lessons with manipulative materials are important at the elementary school levels, and at the upper elementary school levels. Research conducted by Driscoll (1983) found that results at every grade level support the importance of manipulative activity lessons. Driscoll (1983) argued that manipulatives have a place in the intermediate grades both in developing new mathematical concepts and skills and in providing remedial help to students who may be struggling.

The use of manipulatives in teaching mathematics has developed over time. Golfashani (2013) noted that teaching mathematics have moved from using beans or counters to linking cubes, fractions circles and other technologies. Johnson (1993) stated, "With the increased use of manipulatives, a new attitude is evolving towards mathematics. Mathematics is no longer a set of concrete rules to follow but rather a way of thinking. There are now reasons behind the rules" ( $p$. 11). Through many studies manipulatives have shown to be beneficial in mathematics. Ralphael and Wahlstrom (1989) found that teachers, reporting use of a variety of instructional aids, covered more content, and the use of these aids was found to strongly relate to student achievement in topics such as geometry, ratio, proportion, and percent.

Research conducted by Moyer, 2001 indicated that teachers play an important role in creating mathematical environments that provide students with representatives that enhance their thinking. Vinson (2001) stated, "using appropriate and concrete instruction materials is necessary to ensure that children understand mathematical concepts" (p. 91). Moyer and Jones (2004) completed a study of 10 female middle grades teachers during a summer institute with additional research completed at the schools of the participants. Their study indicated the value of empowering teachers towards the benefits of instruction using manipulatives. This research revealed that the students used manipulatives to aid their learning. These authors noted that "in this study students began to see these materials as one of many tools in their mathematics environment and spontaneously and selectively used the materials effectively to mediate their learning" (Moyer \& Jones, 2004, p.30). It is evident that additional research on the impact of teacher knowledge about the use and benefits of manipulatives as it pertains to instruction is needed.

Swan and Marshall (2010) revisited research on the use of manipulatives in schools. They looked at different ways in which teaching of mathematics and the subsequent learning via the use of manipulatives occurred. Swan and Marshall found that there are potential gains to be made by using mathematics manipulative materials where appropriate and employed in a systematic manner. A further study involving students from Grade 3 and 4 by Burns and Hamm (2011) concluded that manipulatives reinforced math concepts and increased average test scores. More recently, the use of manipulatives has proven to be beneficial to improve learning in preschool children. A study conducted by Björklund (2014) found that manipulatives aided learning in children as young as one and two. Björklund concluded that some manipulative objects seem to encourage certain occupations that emphasise specific learning objects more than others.

Balka (1993) indicated that by using manipulatives, students made mathematical connections that would have otherwise gone unnoticed. More current research studies (Bjorklund, 2014; Burns \& Hamm, 2011; Freer, 2006; Swan \& Marshall, 2010) provided evidence that the use of manipulatives allows students to better understand the abstract concepts of mathematics and to achieve improved results.

In short, within the literature, there appears to be a dichotomy of viewpoints regarding the benefits of using manipulatives to improve mathematic learning. While one group of researchers believes that manipulatives have little effect on improving mathematic learning; another group 
believes this is not the case. Consequently, there remains the unanswered question of whether the use of manipulatives will result in improving learning in mathematics.

\section{Theoretical Framework}

The idea that young children can learn mathematical concepts better through concrete objects comes from the learning theory of Piaget (1970). Piaget's theory of learning is based on his views of constructivism. Driscoll (2005) asserted, "Piaget also called his view constructivism, because he firmly believed that knowledge acquisition is a process of continuous self-construction. That is, knowledge is not out there, external to the child and waiting to be discovered" (p. 191). Driscoll (2005) observed that constructivism is knowledge that is constructed by learners as they attempt to make sense of their experiences. Learners are not just empty vessels waiting to be filled, but rather, they are active organisms seeking meaning.

Golfashani (2013) found that the use of manipulatives can be traced to Piaget's suggestion that children cannot comprehend abstract math through explanations and lectures. Instead, children need experiences with models and instruments in order to grasp the mathematical concepts. Researchers (Driscoll, 2005; Siegler \& Ellis, 1996) summarized Piaget's theory as one in which he argued that children go through four stages of cognitive development. In the first stage or sensorimotor stage, the age range is from birth to two years. In second stage or the preoperational stage, the age range is from two to seven years, and children using symbols and responding to objects characterize this level. The third level, labeled as concrete operational, ranges from seven to eleven years, where children are more capable of thinking logically. At the fourth level of development, the formal operations level at the age range of eleven to twelve, the children are able to demonstrate intelligence through the use of symbols. Kamii and Ewing (1996) argued that Piaget's theory is the only theory in existence that explains children's cognitive development from birth to adolescence. Using Piaget's theory as a framework provides the background for a hypothesis concerning manipulatives as an effective tool for adapting teaching methods to meet the learning styles among children experiencing difficulties with their learning of mathematics.

\section{Methods}

This study took place in a northern Saskatchewan school during the fall of 2016 over a period of two weeks. The first week involved the administration of the pre-test and the second week the post-test. The students came from the town and nearby First Nation's reserve. None of the participants had any learning or physical disabilities.

This study represented a true experimental design because of three factors: manipulation, control and randomization (Creswell, 2009). There is manipulation of a variable by using manipulatives consisting of plastic unifix cubes. Regarding control, the variable is introduced only during the post-test and only to the treatment group. Furthermore, internal validity is increased through random assignment. Random selection was followed, involving Grade 2 students from one elementary school. Random assignment was initiated by selecting the subjects' names out of a hat to be randomly assigned to the two groups. Only one class (treatment group) used manipulatives (plastic unifix cubes) to aid them in their responses to the assessment. This, therefore, was a classic treatment design using a pre-test and post-test to study the cause and effect 
where the independent variable, the use of manipulatives, was examined for its effect on the dependent variable, the test scores. Descriptive statistics were used to summarize the results with respect to the sample data. This included calculating the mean, mode and range of the test results from Grade 2 students within the school.

Inferential statistics were also utilized to look at the difference in comparing an outcome (using manipulatives) across two groups (control and treatment) across a specific time (pre-test to a posttest). Additionally, relationships were considered by focusing on how one variable (using manipulatives) might relate to another (improved tests scores). Specifically, does an increase in one variable co-occur with an increase or decrease in another?

\section{Participants}

There were 20 males and 23 females. The students' ages ranged from six to eight years with the average age range being 6.93 years. The males represented 46.5 percent of the total population whereas the females represented 53.5 percent. There were 22 students in the treatment group consisting of 11 males and 11 females with an ethnicity of 17 First Nations and 5 non-First Nations students. Of the 21 students assigned to the control group, 9 were males and 12 were females with an ethnicity of 8 First Nations and 13 non-First Nations students.

\section{Procedures}

The procedures used in the study included the establishment of a control group (CG) and a treatment group (TG) by random selection of Grade 2 students of two classrooms from the same elementary school. Random assignment was initiated by selecting the subjects' names out of a hat to be randomly assigned to the two groups. The groups were then placed into separate classrooms during the pre- and post-test phases of the study. The treatment group (TG) consisted of 22 students and the control group (CG) consisted of 21 students.

Only one class (TG) used manipulatives (plastic unifix cubes) to aid them in their responses to the post-assessment. The treatment group was given the unifix cubes once, before the post-test with the offer that they could use them if they wanted but no prior practice was given. The pre-test and post-test measures each consisted of 20 addition problems with grouping by tens.

\section{Instrument}

Because no standardized tests could be located for this type of research, assessment tools were created by the researcher and the two Grade 2 teachers whose classrooms were involved in the study. To increase the evidence of validity, the questions were based on a school division-wide math assessment that is given to all Grade 1 students at the end of the mathematical unit on number operations. In addition, the same assessment was used as a diagnostic review tool at the beginning of the Grade 2 mathematical unit on number operations. All grade two teachers taught using the same provincially-approved mathematics textbook and administered the mandated division-wide assessment exams. The manipulative that was used in the study was plastic unifix cubes. Reliability studies utilizing SPSS analytical software were conducted to complete the analysis of the tests. 


\section{Data Analysis}

A one-way ANCOVA analysis was conducted using IBM SPSS version 22, allowing the researcher to look at the effect of one or more factors on the dependent variable (post-test scores), while partialling out or removing the effect of another variable. It is the common analysis for a pre-test and post-test design (Huck \& Mclean, 1975) where the focus is on the dependent variable (post-test) while controlling for the effect of a covariate (pre-test) and for possible confounding factors (gender and ethnicity).

A repeated measures ANOVA, mean gain scores and a multiple regression could also have been other data analysis approaches utilized. However, Huck and McLean (1975) found that a repeated measures ANOVA was shown to provide unclear results, while gain scores analysis was more straightforward, they concluded that a covariance analysis was a more powerful method.

Assumptions for ANCOVA were considered. There was a reasonable correlation (i.e., between .3 and .9) between the covariate (pre-test) and the dependent variable (post-test), [Pearson's correlation $\left.(r)=.81, N=43 ; r=.90, N_{\text {control }}=21 ; r=.38, N_{\text {treatment }}=22\right]$. There was a linear relationship between pre- and post-test scores, as assessed by visual inspection of a scatterplot. There was weak evidence of homogeneity of regression slopes; however, there was no interaction evident. Tests of normality were violated for both the covariate and the dependent variable, as assessed by Shapiro-Wilk's test $(\mathrm{p}<.05)$ whereas a significance level greater than .05 was needed to be normal. While there appeared to be heterocedasticity of variance in a visual inspection of the scatterplot, there was homogeneity of variance as assessed Levene's test of homogeneity of variance $(p=.081)$ including pre-test and post-test variables. We failed to reject the null hypothesis that the variances were different at an alpha of .05. There was one outlier in the data with too low of a score on both the pre- and post-test. However, as the student was part of the class, the student's data was included in the study.

\section{Descriptive Results}

Results

Participants of this study consisted of 43 Grade 2 students at a rural elementary school in northern Saskatchewan. Appendix A: Table 1 provides percentages for participants' demographic categorical variables: gender (male and female) and ethnicity (First Nation and non-First Nation). The gender number within the control group and treatment group was slightly around the midpoint of fifty percent. However, the percentage of First Nations in the treatment group was higher than the control group. Lastly, the average age of the treatment group (6.77) as compared to the control group (6.80) differed in that the control group was on average slightly younger. Descriptive statistics show the mean and standard deviation of the covariate (i.e., pre-test scores) and the dependent continuous ratio variable (i.e., post-test scores) for the treatment group and the control group.

Appendix A: Table 2 provides the descriptive information revealing the pre-test and post-test scores, means and standard deviation by gender and ethnicity. The results appear to show an increase in the mean post-test score. The mean final post-test score of the treatment group $(\mathrm{M}=$ $97 \%, 19.4$ out of 20) was higher than the mean final post-test score of the control group $(\mathrm{M}=79 \%$, 15.8 out of 20$)$. 
Interestingly, the students who were randomly selected for the treatment group achieved higher pre-test scores than the control group. This is noteworthy due to the understanding that it is important to control for pre-test scores that score prior math performance when examining students' differences in performance with and without manipulative (post-test comparison of treatment and control group).

Appendix B: Figure 1 illustrates the pre-test and post-test mean percentage scores between the control group and the treatment group. The post-test mean percentage scores for the treatment group were higher than those of the control group.

As the gender variable did not have significant effect on the outcome, it was removed from subsequent analysis. Thus, the ANCOVA examined the effect of treatment (manipulatives) versus control on post-test scores controlling for ethnicity. The one-way ANCOVA indicates that treatment (use of math manipulatives) had a significant effect on post-test scores $F(1,42=28.33$, $p=<0.001$ ) and explained $42 \%$ of the variance in post-test results (partial eta ${ }^{2}=.42$ ) even when controlling for pre-test and ethnicity (see Appendix A: Table 3). Overall, this model accounted for $84 \%$ of the variance in the post-test scores. This finding supports the hypothesis that Grade 2 students who used manipulatives had higher post-test scores.

Appendix A: Table 2 shows that the mean post-test scores of the treatment group ( $M=97 \%)$ were higher than the mean test scores of the control group $(\mathrm{M}=79 \%)$ when taking into consideration the initial pre-test scores and their ethnicity. Thus, the post-test scores of the students in the treatment group who used manipulatives were 18 percentage points higher than the test scores of the participants in the control group who were not allowed to use manipulatives during the post-test. These results were further validated by an Analysis of Covariance (ANCOVA) test found in Appendix A: Table 3. Appendix A: Table 3 shows an ANCOVA result of $F(1,42=$ 28.33, $p=<0.001$, partial eta ${ }^{2}=.42$ ). This means that significance value of less than 0.001 existed for the post-test between the control and treatment groups. This tells us that the probability of obtaining this value by chance is 1 in 1000. The probability falls well under our alpha cut off range of acceptability that was established earlier at 1 in $20(\alpha=0.05)$. This means that our hypothesis of a group difference with the post-test is indeed supported. Thus, the results of this study did support the hypothesis that the scores in the post-test for the participants in the treatment group would be significantly higher than the scores of the participants in the control group.

\section{Discussion}

To summarize, this study began by asking the question: Are there group differences in the post measure test scores between students who used manipulatives and those students who did not when controlled for their pre-test scores, gender and ethnicity? This study provided support for the belief that manipulatives had a positive effect on Grade 2 mathematical achievement in addition tests while controlling for gender, ethnicity and pre-test scores. Consequently, manipulatives do offer benefits to students. This study provides evidence that those students who used mathematical manipulatives performed better on the post-test than those who did not use manipulatives.

\section{Additional Contributions Of This Research}

The results of the study do complement the findings of other research on using mathematical manipulatives, particularly the research conducted by Balka (1993), Björklund (2014), Burns and 
Hamm (2011), DeLoach, Sudder and Uttal (1997), Driscoll (1983), Freer (2006), Gauthier et al., (2004), Raphael and Wahlstrom (1989), Sowell (1989), and Swan \& Marshall (2010). These studies focused on research where using manipulatives with elementary and middle school students resulted in an increase in student achievement. This study is unique in that the intervention was minimal but still revealed strong results. A study such as this supports the belief that if students use mathematical manipulatives, not only does it increase their mathematical achievement scores, but it also provides them with additional methods or strategies that are critical to building problem solving skills.

The results of this study suggest that the use of mathematical manipulatives in answering mathematical problems would be an asset to improving the students' learning and development. Golafshani (2013) stated, "The fact that every classroom consists of students with different levels of ability to understand mathematical concepts means that teachers should focus on using multiple teaching strategies so that all students can benefit" (p. 139). This is something that all educators should consider with their mathematical programs in assisting students to achieve higher academic success. Eventually students will not only be more prepared to handle the demands at school, but also the later requirements of university, jobs and life. Ultimately, this study further supports the broader claim that students who are allowed to use manipulatives to answer mathematical problems will achieve better test scores than those who do not use manipulatives.

\section{Limitations}

This study revealed three limitations. Firstly, tests of normality of the sample were violated which is an important assumption of the ANCOVA analysis. The lack of a formal and recognized standardized test that could be used and repeated in the study posed a hindrance. One was created based on division wide assessment exams. Future research could consider the development of a test that was more difficult and more items to attain a greater distribution of scores.

Secondly, the size of the population in the treatment and control group was small. Only 43 Grade 2 students and only one elementary school were utilized for this study. Thus, one is limited in its ability to generalize to greater populations. Furthermore, the population and thus the sample contained no students with disabilities. The potential effects of manipulatives on mathematic learning for the population deserve to be looked at in the future. A positive finding provides some motivation to develop and further this research. The intervention provided students only the manipulative during the post-test. Future research can further examine the relative benefit of such an intervention compared to larger changes in teaching strategies.

Additional research into the effects of using manipulatives with specific genders remains unclear. This study was unable to analyze gender due to non-normality in the data, and did not include a measure of students' preferred learning styles. Future research is required to shed light upon the degree to which manipulatives differentially improve the instruction and learning of mathematics within education for specific gender and learning styles. These insights would prove beneficial to the instruction and learning of mathematics in the long term.

\section{Conclusion}

In an era when the demands for better schools, higher student learning, and school accountability are intense, any factor that directly affects an increase in student learning must be 
taken seriously. A primary goal of education is to improve and extend student learning. Ultimately, a study such as this supports the belief that when students use mathematical manipulatives, not only does it increase their mathematical achievement scores, but it may also provide them with additional methods or strategies that are critical to building problem solving skills. The results of this study suggest that the use of mathematical manipulatives in answering mathematical problems would be an asset to improving the students' learning and development. The goal is for students to be able to handle the demands at school, but also the later requirements of university, jobs and life. 


\section{References}

Balka, D. (1993). Making the connections in mathematics via manipulatives. Contemporary Education, 65(1), 19-23.

Björklund, C. (2014). Less is more - mathematical manipulatives in early childhood education. Early Child Development and Care, 184(3), 469-485.

Burns, B. A., \& Hamm, E. M. (2011). A comparison of concrete and virtual manipulative use in third-and fourth-grade mathematics. School Science and Mathematics, 111(6), 256-261.

Carbonneau, K. M., Marley, S., \& Selig, J. (2013). A meta-analysis of the efficacy of teaching mathematics with concrete manipulatives. Journal of Educational Psychology, 105(2), 380-400. doi:10.1037/a0031084

CBC News, (2016). Saskatchewan students lag behind all provinces in reading, science, math. Retrieved from http://www.cbc.ca/news/canada/saskatchewan/sask-studentsinternational-test-poor-performance-1.3885549

Creswell, J. (2009). Research design: Qualitative, quantitative and mixed methods approaches. Thousand Oakes, CA: Sage.

DeLoache, J., Schudder, K., \& Uttal, D. (1997). Manipulatives as symbols: A new perspective in the use of concrete objects to teach mathematics. Journal of Applied Developmental Psychology, 18(1), 37-54.

Driscoll, M. (1983). The role of manipulatives in elementarty school mathematics. In M. Driscoll (Ed.), Reserach within reach: Elementary school mathemathematics (pp. 21-28). Reston, Virgina: National Council of Teachers on Mathematics.

Driscoll, M. P. (2005). Psychology of learning for instruction ( $3^{\text {rd }}$ ed). Toronto: Allyn and Bacon.

Eastman, P. E., \& Barnett, J. (1979). Further study of the use of manipulatives with prospective teachers. Journal for Research in Mathematics Education, 10(3), 211-213.

Fennema, E. (1972). The realtive effectiveness of a symbolic and a concrete model in learning a selected mathematics principle. Journal for Research in Mathematics Education, 3(4), 233-238.

Freer, D. (2006). Keeping it real: The rationale for using math manipulatives in the middle grades. Mathematics teaching in the middle school, 11(5), 238-242.

Friedman, M. (1978). The manipulative materials strategy: The latest Pied Piper? Journal for Research in Mathematics Education, 9(1), 78-80.

Gauthier, R., Lawson, A., Connelly, R., Dawson, R., Enns, E., Gagnon, A., ...Smith, L. (2004). Teaching and learning mathematics. The report of the expert panel on mathematics in grades 4 to 6 in Ontario. Ontario, Canada: Ontario Ministry of Education. Retrieved from http://www.edu.gov.on.ca/eng/document/reports/numeracy/panel/numeracy.pdf

Golafshani, N. (2013) Teachers' beliefs and teaching mathematics with manipulatives. Canadian Journal for Education, 36(3), 137-159.

Huck, S., \& McLean, R. (1975). Using a repeated measures ANOVA to analyze the data from a pre-test-post-test design: A Potentially confusing task. Psychological Bulletin, 82(4), 511518.

Johnson, K. (1993). Manipulatives allow everyone to learn mathematics. Contemporary Education, 65(1), 10-11.

Kamii, C., \& Ewing, J. (1996). Basic teaching on Piaget's constructivism. Childhood Education, $72(5), 260$.

Kieren, T. (1969). Activity Learning. Review of Educational Research, 39(4), 509-522. 
Levin, B. (2001). Reforming education: From origins to outcomes. London: Routledge Falmer. Moyer, P. S. (2001). Are we having fun yet? How teachers use manipulatives to teach mathematics. Educational Studies in Mathematics, 47(2), 175-197.

Moyer, S., \& Jones, G. (2004). Controlling choice: Teachers, students, and manipulatives in mathematics classrooms. School Science and Mathematics, 104(1), 16-31.

Mura, R. (1995). Images of mathematics held by university teachers of mathematics education. Educational Studies in Mathematics, 28(4), 385-399.

Parham, J. L. (1983). A meta-analysis of the use of manipulative materials and student achievement in elementary school mathematics. Dissertation Abstracts International, 44A(96), 1-63. (UMI No. 83124771)

Piaget, J. (1970). The science of education and the psychology of the child. New York: Grossman.

Raphael, D., \& Wahlstrom, M. (1989). The influence of instructional aids on mathematics achievement. Journal for Research in Mathematics Education, 20(2), 173-190.

Siegler, R., \& Ellis, S. (1996). Piaget on childhood. Psychological Science, 7(4), 211-215.

Schmoker, M. (2004). Tipping point: From freckless reform to substantive instructional improvement. Phi Delta Kappan, 85(6), 424-432.

Schwahn, C., \& Spady, W. (1998). Why change doesn't happen and how to make sure it does. Educational Leadership, 55(7), 45-47.

Sowell, E. (1989). Effects of manipulative materials in mathematics instruction. Journal for Research in Mathematics Education, 20(5), 498-505.

Suydam, M., \& Higgins, J. (1977). Activity based recommendations from research. Columbus, Ohio: ERIC Center for Science, Mathematics, and Environmental Education.

Swan, P. \&. Marshall, L. (2010). Revisiting mathematics manipulative materials. Australian Primary Mathematics Classroom, 15(2), 13-19.

Vinson, B. (2001). A comparison of pre-service teachers' mathematics anxiety before and after a methods class emphasizing manipulatives. Early Childhood Education Journal, 29(2), 8994.

Weiss, D. (2006). Keeping it real: The rationale for using math manipulatives in the middle grades. Mathematics teaching in the middle school, 11(5), 238-242. 
Table 1

$$
\text { Appendix A: Tables 1, 2, \& } 3
$$

Descriptive Statistics

\begin{tabular}{|c|c|c|c|c|c|c|c|}
\hline & \multirow{2}{*}{$\begin{array}{l}\text { Gender } \\
\text { Male }\end{array}$} & \multicolumn{2}{|c|}{ Ethnicity } & \multicolumn{4}{|c|}{ Age } \\
\hline & & Female & $\begin{array}{l}\text { First } \\
\text { Nations }\end{array}$ & $\begin{array}{l}\text { Non-First } \\
\text { Nations }\end{array}$ & 6 & 7 & 8 \\
\hline Control Group & $45 \%$ & $52 \%$ & $32 \%$ & $72 \%$ & $75 \%$ & $43 \%$ & $40 \%$ \\
\hline $\begin{array}{l}\text { Treatment } \\
\text { Group }\end{array}$ & $55 \%$ & $48 \%$ & $68 \%$ & $28 \%$ & $25 \%$ & $57 \%$ & $60 \%$ \\
\hline
\end{tabular}

Table 2

Descriptive Statistics of Test Means by Gender and by Ethnicity

\begin{tabular}{|c|c|c|c|c|c|c|c|}
\hline & & Pre-Test & & & Post-Test & & \\
\hline & & $\begin{array}{l}\text { Percentage } \\
\text { Score }\end{array}$ & Mean & $S D$ & $\begin{array}{l}\text { Percentage } \\
\text { Score }\end{array}$ & Mean & $S D$ \\
\hline \multirow{5}{*}{$\begin{array}{l}\text { Control Group } \\
N=21\end{array}$} & All & $77.5 \%$ & 15.5 & 4.18 & $79.0 \%$ & 15.8 & 3.12 \\
\hline & Female & $76.7 \%$ & 15.3 & 4.81 & $78.3 \%$ & 15.7 & 3.39 \\
\hline & Male & $78.3 \%$ & 15.7 & 3.43 & $80.0 \%$ & 16.0 & 2.92 \\
\hline & First Nations & $78.8 \%$ & 15.8 & 3.06 & $82.5 \%$ & 16.5 & 1.60 \\
\hline & $\begin{array}{l}\text { Non-First } \\
\text { Nations } \\
\end{array}$ & $76.5 \%$ & 15.3 & 4.85 & $76.9 \%$ & 15.4 & 3.78 \\
\hline \multirow{5}{*}{$\begin{array}{l}\text { Treatme } \\
N=22\end{array}$} & All & $86.5 \%$ & 17.3 & 1.62 & $97.0 \%$ & 19.4 & 0.73 \\
\hline & Female & $88.6 \%$ & 17.7 & 1.27 & $95.9 \%$ & 19.2 & 0.87 \\
\hline & Male & $84.5 \%$ & 16.9 & 1.87 & $97.7 \%$ & 19.5 & 0.52 \\
\hline & First Nations & $85.6 \%$ & 17.1 & 1.69 & $97.1 \%$ & 19.4 & 0.71 \\
\hline & $\begin{array}{l}\text { Non-First } \\
\text { Nations }\end{array}$ & $90.0 \%$ & 18.0 & 1.22 & $96.0 \%$ & 19.2 & 0.84 \\
\hline
\end{tabular}

Table 3

Inferential Statistics Results from an ANCOVA Analysis

\begin{tabular}{lllllll}
\hline Source & $\begin{array}{l}\text { Type III Sum of } \\
\text { Squares }\end{array}$ & $D f$ & Mean Square & $F$ & Sig. & $\begin{array}{l}\text { Partial } \\
\text { Squared }\end{array}$ \\
\hline $\begin{array}{l}\text { Corrected } \\
\text { Model }\end{array}$ & $290.42^{\mathrm{a}}$ & 3 & 96.81 & 73.13 & $<.001$ & .85 \\
\hline Intercept & 84.46 & 1 & 84.46 & 63.80 & $<.001$ & .62 \\
\hline Pre-test & 150.14 & 1 & 150.14 & 113.41 & $<.001$ & .74 \\
\hline Ethnicity & 5.69 & 1 & 5.69 & 4.30 & .045 & .10 \\
\hline CGTG & 37.51 & 1 & 37.51 & 28.33 & $<.001$ & .42 \\
\hline Error & 51.63 & 39 & 1.32 & & & \\
\hline Total & 13704.00 & 43 & & & & \\
\hline $\begin{array}{l}\text { Corrected } \\
\text { Total }\end{array}$ & 342.05 & 42 & & & & \\
\hline
\end{tabular}

Brock Education Journal, 26(2), 2017 


\section{Appendix B: Figure 1}

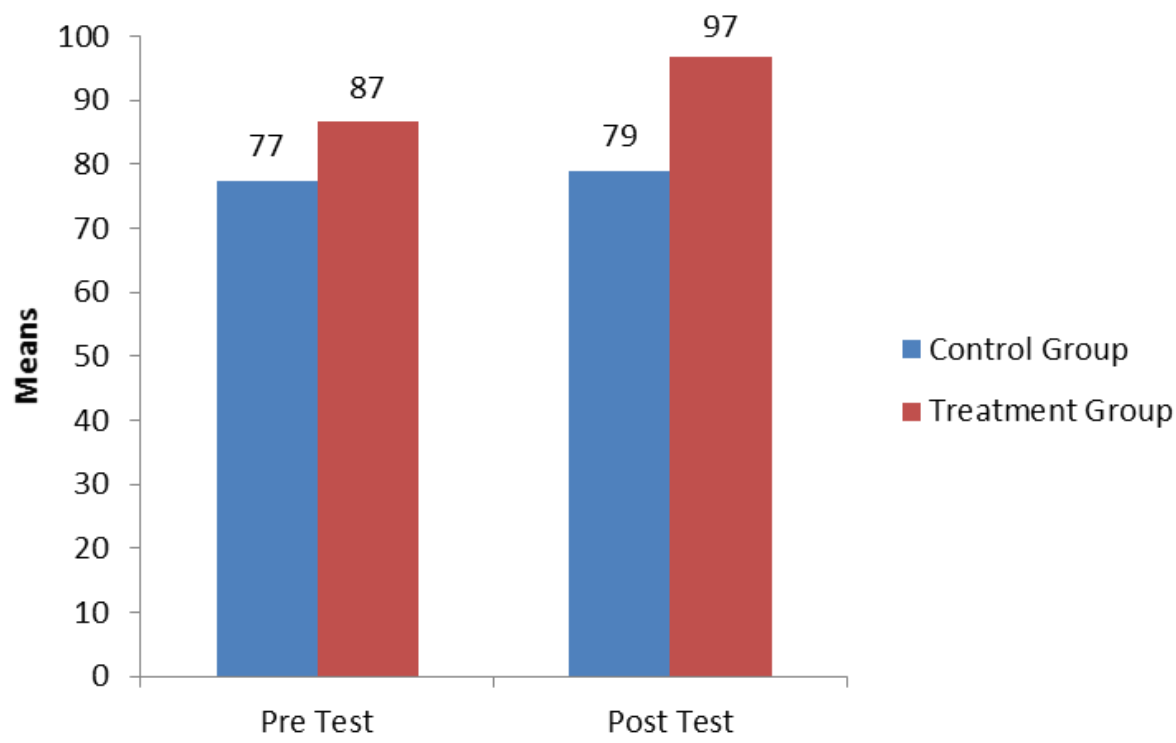

Figure 1. Pre-and post percentage means between control group and treatment group. 